\title{
Vancomycin dosing
}

\section{assessment in intensive care}

unit patients based on a

population pharmacokinetic/

pharmacodynamic

\section{simulation}

Natalia Revilla, ${ }^{1}$ Ana Martín-Suárez, ${ }^{2}$ Marta Paz Pérez, ${ }^{3}$

Félix Martín González ${ }^{3}$ \& María del Mar Fernández de Gatta²

${ }^{1}$ Service of Pharmacy and ${ }^{3}$ Intensive Care Unit, University Hospital of Salamanca and ${ }^{2}$ Department of

Pharmacy and Pharmaceutical Technology, University of Salamanca, Salamanca, Spain
Correspondence

Professor María del Mar Fernández de Gatta, Departamento de Farmacia y

Tecnología Farmacéutica, Facultad de Farmacia, Avda. Lcdo. Méndez Nieto,

37007 Salamanca Spain.

Tel.: +34 923294536

Fax:+34923294515

E-mail:gatta@usal.es

Keywords

$\operatorname{AUC}(0,24 \mathrm{~h}):$ MIC, dosage

individualization, intensive care unit, population pharmacokinetics,

pharmacokinetics/pharmacodynamics or PK/PD, vancomycin

\section{Received}

2 June 2009

Accepted

10 January 2010

\section{WHAT IS ALREADY KNOWN ABOUT THIS SUBJECT}

- Despite the frequent use of vancomycin in intensive care unit (ICU) patients, few studies aimed at characterizing vancomycin population pharmacokinetics have been performed in this critical population. - Population pharmacokinetics coupled with pharmacodynamic analysis, in order to optimize drug exposure and hence antibacterial effectiveness, has been little applied in these specific patients.

\section{WHAT THIS STUDY ADDS}

- Our population model characterized the pharmacokinetic profile of vancomycin in adult ICU patients, higher distribution volume values ( $V$ ) being observed when the patient's serum creatinine $\left(\mathrm{Cr}_{\mathrm{se}}\right)$ was greater than $1 \mathrm{mg} \mathrm{dl}^{-1}$. - Age and creatinine clearance $\left(\mathrm{CL}_{\mathrm{c}}\right)$ were identified as the main covariates explaining the pharmacokinetic variability in vancomycin CL. - Our pharmacokinetic/pharmacodynamic (PK/PD) simulation should aid clinicians to select initial vancomycin doses that will maximize the rate of response in the ICU setting, taking into account the patient's age and renal function as well as the susceptibility of Staphylococcus aureus.

\section{AIM}

To estimate the vancomycin pharmacokinetic profile in adult ICU patients and to assess vancomycin dosages for increasing the likelihood of optimal exposure.

\section{METHODS}

Five hundred and sixty-nine concentration-time data from 191 patients were analysed using a population pharmacokinetic approach (NONMEN ${ }^{\mathrm{TM}}$ ). External model evaluation was made in 46 additional patients. The $24 \mathrm{~h}$ area under the concentration-time curve $(\operatorname{AUC}(0,24 \mathrm{~h}))$ was derived from the final model. Minimum inhibitory concentration (MIC) values for $S$. aureus were obtained from the EUCAST database. $\mathrm{AUC}(0,24 \mathrm{~h})$ : MIC $\geq 400$ was considered as PK/PD efficacy index. The probability of different dosages attaining the target considering different strains of $S$. aureus and patient subgroups was estimated with Monte Carlo simulation.

\section{RESULTS}

Vancomycin $\mathrm{CL}$ showed a significant dependence on patient age and renal function whereas $\mathrm{Cr}_{\mathrm{se}}>1 \mathrm{mg} \mathrm{dl}^{-1}$ increased $V$ more than twofold. For our representative ICU patient, 61 years, $73 \mathrm{~kg}, \mathrm{Cr}_{\mathrm{se}}=1.4 \mathrm{mg} \mathrm{dl}^{-1}$, measured $\mathrm{CL}_{\mathrm{Cr}}$ $=74.7 \mathrm{ml} \mathrm{min}{ }^{-1}$, the estimated values were $\mathrm{CL}=1.06 \mathrm{ml} \mathrm{min} \mathrm{mg}^{-1}$ and $V=$ $2.04 \mathrm{I} \mathrm{kg}^{-1}$. The cumulative fraction of response for a standard vancomycin dose $\left(2 \mathrm{~g} \mathrm{day}^{-1}\right)$ was less than $25 \%$ for VISA strains, and $33 \%$ to $95 \%$ for susceptible $S$. aureus, depending on patient characteristics.

\section{CONCLUSIONS}

Simulations provide useful information regarding the initial assessment of vancomycin dosing, the conventional dosing regimen probably being suboptimal in adult ICU patients. A graphic approach provides the recommended dose for any selected probability of attaining the PK/PD efficacy target or to evaluate the cumulative fraction of response for any dosing regimen in this population. 


\section{Introduction}

Patients admitted to the ICU often require antibiotic therapy to treat complicated infections. More than $70 \%$ of Staphylococcus aureus isolates in ICUs are methicillinresistant, and vancomycin has long been the gold standard for presumed or known infections caused by this pathogen [1]. In the critical care setting, high rates of antimicrobial resistance raise the risk of poor outcomes. Several studies have reported almost twice the mortality in patients infected by a pathogen not effectively treated with empirical antibiotic regimens [2-5]. Moreover, in critically ill patients several pathophysiological conditions that alter drug disposition and increase their pharmacokinetic variability could lead to drug underexposure if they are not taken into account [6].

Optimizing antibiotic exposure by linking pharmacokinetic and pharmacodynamic principles may improve antimicrobial effectiveness and the quality of care [7]. For vancomycin, the $\operatorname{AUC}(0,24 \mathrm{~h})$ : MIC ratio seems to be the $\mathrm{PK} / \mathrm{PD}$ index that is best correlated with efficacy. A strong correlation between such an index and the clinical and bacteriological responses to vancomycin in patients with lower respiratory tract infections has been demonstrated, suggesting its use as a surrogate marker when determining vancomycin dosage regimens or treatment failure [8]. A recent paper focusing on the most appropriate vancomycin regimens for treating methicillin-resistant S. aureus ventilator-associated pneumonia also supports pharmacodynamic concepts in the use of vancomycin [9]. However, for this antibiotic the best dosing regimen according to PK/PD principles has been little considered [10-12]. The application of population kinetics with PK/PD analysis based on Monte Carlo simulation is an excellent tool for defining dosage strategies aimed at estimating the likelihood that the antibiotic will effectively treat a specific cohort of patients [13]. This integrated approach allows consideration of the variability in pharmacokinetic parameters and also in the susceptibility of the target pathogen. In order to obtain a more realistic picture of therapeutic outcomes, a well defined population PK model obtained from a specific cohort of patients is crucial because variability in the MIC can be obtained from surveillance studies [14]. The nonlinear mixed-effect approach implemented in the NONMEM ${ }^{\mathrm{TM}}$ software is the most reliable and frequent methodology in population PK analysis [15]. To our knowledge, only one previous study in a small population of ICU patients has used such an approach for vancomycin modelling [16]. On the basis of this, the aims of this study were to develop and validate a population PK model for vancomycin in a large number of ICU patients, and to assess, by Monte Carlo simulation, the vancomycin dosages required to increase the probability of attaining a target PK/PD index in this critically ill population.

\section{Methods}

\section{Patients and study design}

Adult ( $\geq 18$ years old) vancomycin-treated patients admitted to the medical ICU of the University Hospital of Salamanca (an 837-bed teaching hospital) over a period of 6 years (1999-2004) were enrolled in this retrospective, noncomparative study. Patients with neoplasic disorders, prior cardiac surgery, renal replacement therapy, and those for whom vancomycin concentration-time data were unavailable were excluded after a review of their clinical history. In the population selected for model building (191 patients), the data carefully recorded for each patient were age, gender, exitus, main diagnosis at discharge and the Acute Physiology and Chronic Health Evaluation System (APACHE II) score within $24 \mathrm{~h}$ after admission to the ICU [17]. Total body weight, height, mechanical ventilation status, nutritional support, fluid balance, serum albumin, $\mathrm{Cr}_{\mathrm{Se}}, 24 \mathrm{~h}$-measured $\mathrm{CL}_{\mathrm{Cr}}$ and concurrent administration of diuretics and vasoactive drugs were recorded throughout the patients' stay in the ICU. When the measured $\mathrm{CL}_{\mathrm{cr}}$ was unavailable ( $8 \%$ of data) the $\mathrm{CL}_{\mathrm{cr}}$ estimated with the Levey formula was obtained [18]. For $\mathrm{Cr}_{\mathrm{se}}$ and serum albumin, quantification/sensitivity limits of $0.5 \mathrm{mg} \mathrm{dl}^{-1}$ and $1 \mathrm{mg} \mathrm{dl}^{-1}$ were assumed, respectively. No covariate had more than $20 \%$ of missing values. For missing value imputation the mean patient or population value was assumed.

Data acquisition for the validation population (46 patients, 73 concentration data) was accomplished after the population analysis had been completed (over period 2007-2008), so only selected covariates were recorded.

Data pertaining to vancomycin therapy and plasma concentrations were obtained from the database of the Clinical Pharmacokinetics Service of the hospital, which included the precise timing of drug dosing and blood sampling.

Approval from the Institutional Review Board of the hospital was obtained. Informed patient consent was unnecessary because the study involved the collection of routine clinical data.

\section{Blood sampling and vancomycin assays}

Vancomycin TDM guidelines at the University Hospital of Salamanca establish the measurement of trough concentrations and recommend that the timing of the first monitoring should be after the third dose.

A total of 569 measured vancomycin concentrations were recorded, mostly $(79.8 \%)$ corresponding to $C_{(\mathrm{min})}$ values (0-60 min pre-dose). The number of concentration data per patient ranged from 1 to 19 (mean $=2.98$ ).

Vancomycin plasma concentrations were measured by fluorescence polarization immunoassay (AxSYM; Abbott Laboratories, Abbott Park, EEUU). The quantification limit was $2.00 \mathrm{mg} \mathrm{l}^{-1}$ and the intra- and inter-assay coefficients of variation were $<7 \%$ over the entire calibrator range ( 7 to $\left.75 \mathrm{mgl}^{-1}\right)$. The external quality control used was Unity 
(Bio-Rad Laboratories). Concentrations at or below the quantification limit were not considered in the study.

Population pharmacokinetic analysis

Population PK analysis quantifies the variability among individuals in the population for a particular model, and attempts to explain them based on individual dependent covariates. The concentration vs. time data for vancomycin were analysed with the nonlinear mixed effects modelling approach [19], using NONMEM ${ }^{\mathrm{TM}}$ (Version 5, level 1.1, GloboMax LLC, Hanover, MD, USA). The first-order conditional estimation method with interaction (FOCE INTERACTION) was used, and the ADVAN1 TRANS2 subroutines were applied. Only the fits in which convergence with the estimation of the variance-covariance matrix was reached were considered. A one-compartment model with zeroorder input and first-order elimination was assumed as the basic structural model because the available information (nearly $80 \%$ of the measured concentrations being taken at $\left.C_{(\min )}\right)$ did not allow a more realistic two-compartment model. The parameters of the structural model were $\mathrm{CL}$ and $V$.

Several error models were investigated to describe the inter-subject and residual variability. The former, which quantifies differences between individual and population parameters, was finally modelled as an exponential random effect by the following equations:

$$
\mathrm{CL}_{\mathrm{ij}}=\mathrm{CL} \times \mathrm{e}^{\eta \mathrm{CL}} V_{\mathrm{ij}}=V \times \mathrm{e}^{\eta V}
$$

where $\mathrm{CL}_{\mathrm{ij}}$ and $V_{\mathrm{ij}}$ denote the parameter for the $\mathrm{i}^{\text {th }}$ subject, $\mathrm{CL}$ and $V$ the mean value of parameters for the population, and $\eta_{C L}$ and $\eta_{v}$ a random inter-individual variable that is normally distributed with zero mean and variance $\omega$. The potential covariance of the parameters was also investigated with full blocks of $\omega s$.

The residual unexplained variability was finally modelled as an additive error model:

$$
\text { Cobs }_{i j}=\text { Cpred }_{i j}+\varepsilon_{i j}
$$

where Cobs $_{\mathrm{ij}}$ and Cpred $_{\mathrm{ij}}$ denote the $\mathrm{j}^{\text {th }}$ observed and predicted vancomycin concentrations for the $i^{\text {th }}$ subject, respectively, and $\varepsilon_{\mathrm{ij}}$ the $\mathrm{j}^{\text {th }}$ measurement error for the $\mathrm{i}^{\text {th }}$ subject. This error includes model misspecification, errors in reported dosing or sampling times, analytical errors and intra-subject variability. It is assumed to be independent and identically distributed, with a normal distribution around the mean zero and variance $\sigma$.

Model selection was based on the precision of parameter estimates, goodness-of-fit plots, and the minimum value of the objective function (OF) provided by NONMEM $^{\mathrm{TM}}$. A difference of 3.84 and 6.63 points in the OF between two nested models differing in one parameter was significant at the $5 \%$ and $1 \%$ levels, respectively. Since some models compared were not nested, OF was not used directly, and the value of the Akaike Information Criteria (AIC) [20] was used instead.
The potential effect of covariates on the pharmacokinetic parameters was first examined from the NONMEM ${ }^{\mathrm{TM}}$ output results, using the Xpose ${ }^{T M}$ (Version 3.1) package and generalized additive modelling (GAM) to graphically identify the most likely influential covariates. A stepwise forward selection approach was used for covariate inclusion in the population model. A basic population model without covariates was initially selected and each covariate was added individually to this basic model, testing several regression equations. Covariates were included in the model when a significant reduction in OF was obtained $(P<0.05)$. Then, backward elimination was performed. Each covariate was removed independently from the model $(P<0.01)$ to confirm its relevance. This conservative approach ensured that only the most meaningful covariates entered the final model [21].

\section{Model validation}

External validation was used to evaluate the predictive performance of the final population model. This evaluation tool is considered to be more reliable and more robust than internal validation, and the most appropriate method when the final aim is dosage prediction [22]. The population parameters of the final model were used to estimate, using NONMEM ${ }^{\mathrm{TM}}$, individual parameters in the validation data set. From these individual parameters, the concentrations were estimated (the NONMEM ${ }^{\mathrm{TM}}$ 'SIMULATION' option) at the same times as those actually observed and were compared in order to determine their predictive performance. Standardized prediction errors were estimated to evaluate whether the regression model was correct and whether the parameters estimated were unbiased [23]. NONMEM $^{\mathrm{TM}}$ affords these values under the denomination of weighted residuals (WRES), considering in their calculation the population variability that includes the interindividual and residual variability. Likewise, these errors should have a normal distribution with a mean of 0 and variance close to unity.

Additionally, the number of observed concentration data within the defined interval of the predicted concentration data (PRED), such as [PRED $\pm 2 \times$ SDpop], was estimated. Ideally, $95 \%$ of observed concentrations should be within such an interval. The population standard deviation (SDpop) was obtained from the residual (RES) and WRES values of the NONMEM ${ }^{\mathrm{TM}}$ output (SDpop $=|\mathrm{RES} / \mathrm{WRES}|$ ).

\section{Pharmacokinetic-pharmacodynamic simulation} On the basis of Monte Carlo simulations, the cumulative fraction of response (CFR) defined as the expected population probability of target attainment for a specific drug dose and a specific population of microorganisms was calculated [24]. The $\operatorname{AUC}(0,24 \mathrm{~h})$ : MIC ratio was the goal for vancomycin treatment optimization and a value of $\geq 400$ was fixed as the target [8]. CFR values are an estimate of the proportion of the simulated population achieving such a value of the PK/PD index (AUC(0,24 h) :MIC $\geq 400)$. Monte 
Carlo simulation aims to assess whether the attainment of the efficacy index differed significantly not only depending on the daily vancomycin dose (from 1000 to $5000 \mathrm{mg}$ day $^{-1}$ ) but also among ICU patients. To this end, since according to our population $\mathrm{PK}$ model $\mathrm{CL}_{\mathrm{cr}}$ and age were the patient covariates influencing clearance and hence vancomycin exposure, simulations in the four subpopulations defined by $\mathrm{CL}_{\mathrm{cr}}$ and age were performed. Thus, our patient population was divided into four subpopulations: patients with age $>65$ years and $\mathrm{CL}_{\mathrm{cr}}<60 \mathrm{ml} \mathrm{min}^{-1}(32.0 \%$ of patients); patients with age $>65$ years and $\mathrm{CL}_{\mathrm{Cr}} \geq$ $60 \mathrm{ml} \mathrm{\text {min}^{-1 }}$ (12.5\% of patients); patients with age $<65$ years and $\mathrm{CL}_{\mathrm{cr}}<60 \mathrm{ml} \mathrm{min}^{-1}$ (24.1\% of patients), and patients with age $<65$ years and $\mathrm{CL}_{\mathrm{cr}} \geq 60 \mathrm{ml} \mathrm{min} \mathrm{m}^{-1}$ (31.4\% of patients). As input in the Monte Carlo simulations individual AUC values were used. The $C L$ derived from the final population model was estimated for each patient using the NONMEM'M 'POSTHOC' option. From these data, the $\operatorname{AUC}(0,24 \mathrm{~h})$ was calculated as the daily dose: $\mathrm{CL}$ ratio. The units used were $\mathrm{mg} \mathrm{l}^{-1} \mathrm{~h}$ for $\mathrm{AUC}(0,24 \mathrm{~h})$ and $\mathrm{I} \mathrm{h}^{-1} \mathrm{~kg}^{-1}$ for $\mathrm{CL}$.

The potential pathogens selected for PK/PD simulations were vancomycin-susceptible and vancomycinintermediate susceptibility (VISA) strains of S. aureus. The MIC values reported for this pathogen by the European Committee on Antimicrobial Susceptibility Testing (EUCAST) database (www.eucast.org) [14] were used, except for the VISA strains [25]; these values are included in Table 1. A log-Gaussian distribution was assumed for the $\operatorname{AUC}(0,24 \mathrm{~h})$ data, and a discrete distribution for MICs. The output consisted of a cumulative probability distribution. Simulation was performed on $10^{4}$ replicates from each subpopulation, using the SimulAr program [26].

\section{Results}

\section{Patient characteristics}

A total of 191 adult ICU patients, 126 males and 65 females (569 concentration-time data values) were available for

\section{Table 1}

Frequency distribution of minimum inhibitory concentration (MIC) for $S$. aureus used in Monte Carlo simulation

\begin{tabular}{|llc|}
\hline $\begin{array}{l}\text { MIC value } \\
\left(\mathrm{mg} \mathrm{l}^{-\mathbf{1}}\right)\end{array}$ & $\begin{array}{l}\text { Frequency (\%) } \\
\text { S. aureus }\end{array}$ & VISA \\
\hline $\mathbf{0 . 1 2 5}$ & 0.08 & - \\
$\mathbf{0 . 2 5}$ & 0.59 & - \\
$\mathbf{0 . 5}$ & 15.15 & - \\
\hline $\mathbf{1}$ & 74.24 & - \\
$\mathbf{2}$ & 9.68 & 31.0 \\
$\mathbf{2 . 5}$ & - & 19.0 \\
$\mathbf{3}$ & - & 44.0 \\
$\mathbf{3 . 5}$ & - & 6.0 \\
$\mathbf{4}$ & 0.26 & - \\
\hline
\end{tabular}

pharmacokinetic modelling. The most prevalent clinical diagnoses were severe trauma $(n=81)$, post-surgery situations $(n=50)$, sepsis ( $n=49$; septic shock was present in 13 septic patients), and respiratory infections and pneumonia $(n=66)$. Thirty-five patients underwent multiorgan failure, 30 developed respiratory distress syndrome, and 15 hypovolaemic shock. Exitus during vancomycin therapy occurred in 69 patients. Mechanical ventilation and parenteral nutritional support were implemented in $87 \%$ and $46 \%$ of patients, respectively, whereas vancomycin concurrent with albumin, furosemide or catecholamines was administered in $21 \%, 64 \%$ and $71 \%$ of patients. Other relevant characteristics of the patient population obtained at the start of vancomycin therapy are summarized in Table 2.

Vancomycin doses were given intravenously either as intravenous infusions over $60 \mathrm{~min}(n=406)$ or continuously $(n=14)$. In the first case, the initial dose was $1000 \mathrm{mg}$

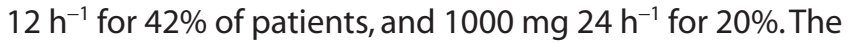
mean number (SD) of administrations per patient was 20.8 (17.6) and the mean value of the doses administered was 18.4 (10.3) $\mathrm{mg} \mathrm{kg}^{-1} \mathrm{day}^{-1}$. The mean duration of the continuous infusion was 17.5 (15.1) days and the mean infusion rate was 56.9 (34.9) $\mathrm{mg} \mathrm{h}^{-1}$. None of the patients received a loading dose. Ten patients received vancomycin in different admission episodes.

The population for model validation (46 patients, 73 concentration data) showed similar characteristics to the patients included for building the model. The mean and SD for age, body weight, $\mathrm{Cr}_{\mathrm{se}}$ and $\mathrm{CL}_{\mathrm{cr}}$ of this population were $58.7 \pm 16.6$ years; $73.1 \pm 19.8 \mathrm{~kg} ; 1.0 \pm 0.7 \mathrm{mg} \mathrm{dl}^{-1}$ and 67.3 $\pm 48.6 \mathrm{ml} \mathrm{min}^{-1}$, respectively.

\section{Population pharmacokinetic analysis}

Generalized additive modelling (GAM) identified the measured $\mathrm{CL}_{\mathrm{Cr}} \mathrm{Cr}_{\mathrm{se}}$, exitus, Apache II score and age as the best

\section{Table 2}

Summary of the demographic and pathophysiological characteristics of the patients included in the model building

\begin{tabular}{|c|c|c|}
\hline Characteristic & Mean \pm SD & Range \\
\hline Age (years) & $61.1 \pm 16.3$ & $18-85$ \\
\hline Total body weight (kg) & $73.0 \pm 13.3$ & $45-150$ \\
\hline Body mass index $\left(\mathrm{kg} \mathrm{m}^{-2}\right)$ & $26.2 \pm 4.1$ & $18.4-43.8$ \\
\hline Apache II score & $18.0 \pm 6.9$ & $2-41$ \\
\hline Serum albumin ( $\left.\mathrm{g} \mathrm{dl}^{-1}\right)$ & $2.3 \pm 0.7$ & $0.5-6.2$ \\
\hline $\mathrm{Cr}_{\mathrm{se}}\left(\mathrm{mg} \mathrm{dl}^{-1}\right)$ & $1.4 \pm 1.0$ & $0.6-5.0$ \\
\hline Measured $\mathrm{CL}_{\mathrm{Cr}}(\mathrm{ml} \mathrm{min}-1)$ & $74.7 \pm 58.0$ & $10-328$ \\
\hline Estimated $\mathrm{CL}_{\mathrm{Cr}}\left(\mathrm{ml} \mathrm{min} \mathrm{min}^{-1}\right)$ & $86.1 \pm 55.1$ & $9.5-230.5$ \\
\hline PEEP $\left(\mathrm{cm} \mathrm{H} \mathrm{H}_{2} \mathrm{O}\right)$ & $7.1 \pm 3.0$ & $2-22$ \\
\hline $\mathrm{FiO}_{2}(\%)$ & $49 \pm 18$ & $25-100$ \\
\hline Fluid balance $(\mathrm{ml})$ & $665 \pm 1808$ & $-5424 / 7701$ \\
\hline Vancomycin therapy duration (days) & $14.7 \pm 16.4$ & $1-113$ \\
\hline Concentration data per patient $(n)$ & $3.0 \pm 2.5$ & $1-19$ \\
\hline
\end{tabular}

APACHE, Acute Physiology and Chronic Health Evaluation System [17]; Estimated $\mathrm{CL}_{\mathrm{Cr}}$, Creatinine clearance estimated by the Levey method [18]; PEEP, positive end-expiratory pressure; $\mathrm{FiO}_{2}$, fraction of inspired oxygen. 


\section{Table 3}

Intermediate models showing the influence of the different covariates in the vancomycin parameters

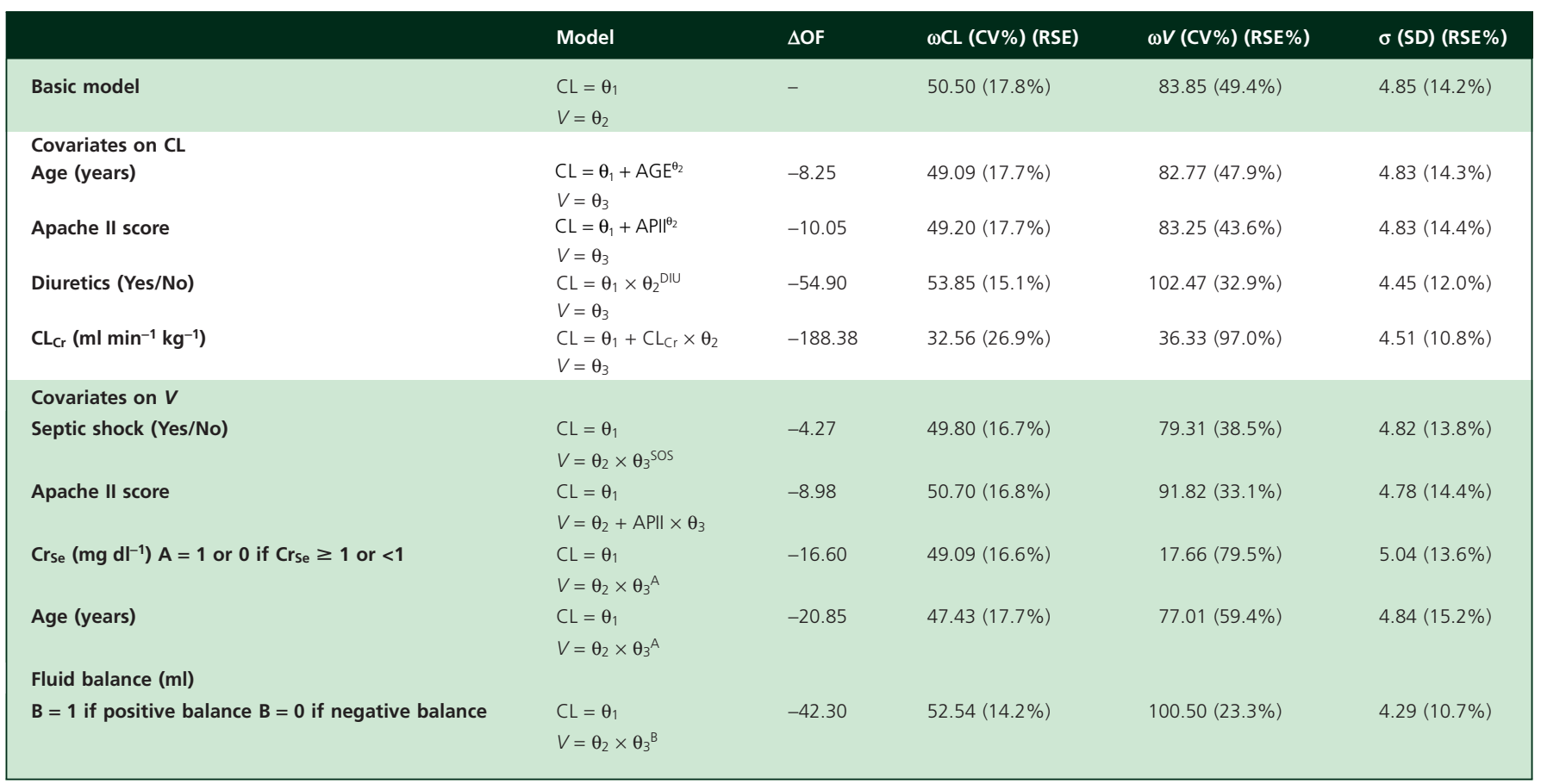

$\triangle O F$, modification in objective function value. $\omega$, interindividual variability expressed as CV\%; $\sigma$, residual variability expressed as standard deviation. RSE \%, relative standard error expressed as a percentage of the variation coefficient.
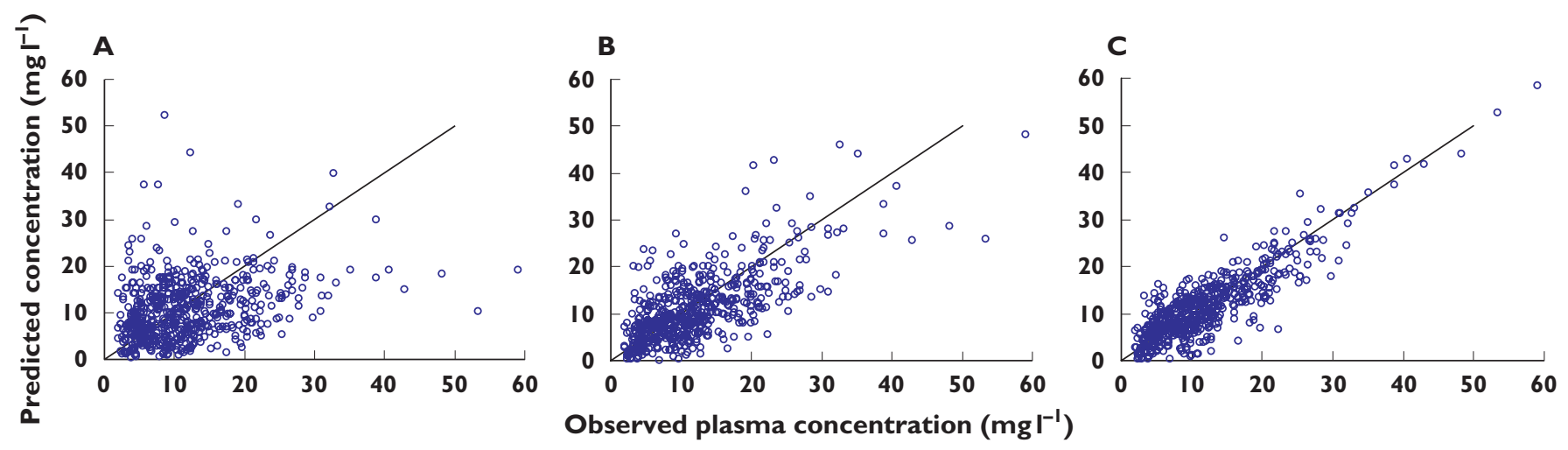

\section{Figure 1}

Goodness-of-fit plots: (A) Population predicted concentrations from basic model; (B) Population predicted concentrations from final model; and (C) Individual predicted concentrations from final model

predictors of vancomycin clearance; and exitus, age, $\mathrm{CL}_{\mathrm{Cr}}$, $\mathrm{Cr}_{\text {se }}$ and fluid balance for $V$. Later, the influence of these covariates on pharmacokinetic parameters was tested with NONMEM ${ }^{\mathrm{TM}}$. Table 3 summarizes the covariates that significantly influence vancomycin disposition by one-byone inclusion in the basic model. Of all the regression equations tested for each covariate, the one that afforded the best results was included.

The following equation describes the final covariate model for vancomycin in our ICU patients: $\mathrm{CL}$ $\left(\mathrm{ml} \mathrm{min}{ }^{-1} \mathrm{~kg}^{-1}\right)=0.67 \times \mathrm{CL}_{\mathrm{cr}}\left(\mathrm{ml} \mathrm{min}{ }^{-1} \mathrm{~kg}^{-1}\right)+$ AGE (years) $)^{-0.24}$

$$
V\left(\mathrm{~kg}^{-1}\right)=0.82 \times 2.49^{\mathrm{A}}
$$

where $\mathrm{A}$ is a dichotomous covariate coded as $\mathrm{A}=0$ if $\mathrm{Cr}_{\mathrm{se}} \leq$ $1 \mathrm{mg} \mathrm{dl}^{-1}$, and $\mathrm{A}=1$ if $\mathrm{Cr}_{\mathrm{se}}>1 \mathrm{mg} \mathrm{dl}^{-1}$.

With respect to analysis of the descriptive performance of the model selected, Figure 1 shows the goodness-of-fit plots obtained for the basic and final models.

Table 4 summarizes the population pharmacokinetic estimates from the basic and final models. All pharmacokinetic parameters of the final model were reliably estimated, since the percentage of relative standard error was 


\section{Table 4}

Summary of results for the basic and final population models

\begin{tabular}{|c|c|c|c|c|}
\hline \multirow[b]{2}{*}{ Parameter } & \multicolumn{2}{|c|}{$\begin{array}{l}\text { Basic model } \\
\text { (OF = 2719.37) }\end{array}$} & \multicolumn{2}{|c|}{$\begin{array}{l}\text { Final model } \\
(\mathrm{OF}=2420.69) \\
\mathrm{CL}=\theta_{1} \times \mathrm{CL}_{\mathrm{Cr}}+\mathrm{AGE}^{\theta_{2}} \\
V=\theta_{3} \times \theta_{4}{ }^{\mathrm{A}} \\
\mathrm{A}=0 \text { or } 1 \text { if } \mathrm{Crse}_{\mathrm{se}} \leq 1 \text { or } \mathrm{Crse}_{\mathrm{se}}>1 \mathrm{mg} \mathrm{dl}^{-1}\end{array}$} \\
\hline & Mean (RSE\%) & $95 \% \mathrm{Cl}$ & Mean (RSE\%) & $95 \% \mathrm{Cl}$ \\
\hline \multicolumn{5}{|l|}{ Structural model } \\
\hline$V, \theta_{3}\left(\mathrm{~kg}^{-1}\right)$ & $3.17(37.9)$ & $5.52,0.82$ & $0.82(2.8)$ & $0.94,0.70$ \\
\hline$V, \theta_{4 C_{\mathrm{re}}}$ & - & - & $2.49(9.9)$ & $2.98,2.00$ \\
\hline \multicolumn{5}{|l|}{ Variance model } \\
\hline Residual (SD, $\mathrm{mg} \mathrm{l}^{-1}$ ) & $4.85(14.2)$ & $5.48,4.12$ & $4.23(9.8)$ & $4.62,3.80$ \\
\hline Intersubject CL (CV\%) & $50.50(17.8)$ & $58.62,40.79$ & $30.13(16.4)$ & $34.64,24.82$ \\
\hline Intersubject $V(C V \%)$ & $83.85(49.4)$ & $117.44,16.37$ & $22.83(38.8)$ & $30.28,11.18$ \\
\hline
\end{tabular}

$\mathrm{OF}$, objective function value; RSE\%, relative standard error expressed as a percentage of the coefficient of variation; Measured $\left.\mathrm{CLcr}_{(\mathrm{ml} \mathrm{min}}{ }^{-1} \mathrm{~kg}^{-1}\right)$; $\mathrm{Crse}_{\mathrm{se}}$ serum creatinine $\left(\mathrm{mg} \mathrm{dl}^{-1}\right)$; $\theta$, regression parameter.

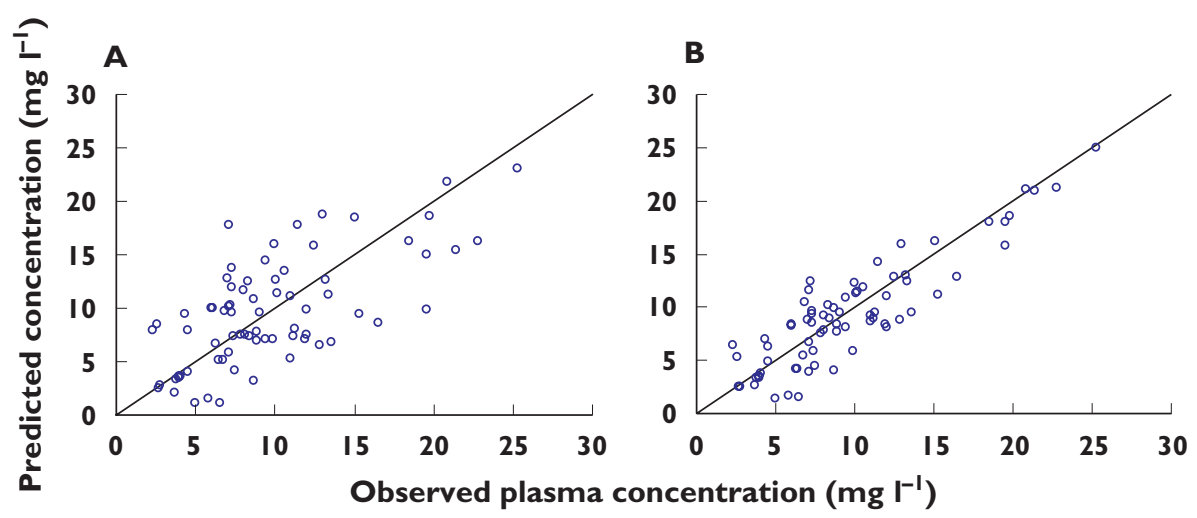

\section{Figure 2}

Plots of model-predicted vs. observed concentrations in validation population for the final model based on: (A) Population parameters estimates and (B) individual parameters estimates

less than $20 \%$, except for $V$. A $20 \%$ decrease in interindividual variability was obtained upon including age and the measured $C_{C r}$ as covariates for the $C L$ regression equation. Consideration of $\mathrm{Cr}_{\mathrm{se}}$ as a dichotomous covariate accounted for nearly $60 \%$ inter-individual variability. The residual variability, expressed as percentages (CV\%) in relation to a mean concentration of $12 \mathrm{mg} \mathrm{l}^{-1}$, was reduced from $41 \%$ to $35 \%$ from the basic to the final model.

\section{Model evaluation}

Regarding the assessment of model performance on the validation population independently, Figure 2 shows the plots of the model-predicted vs. observed concentrations for the final model.

The predictive performance of the final model was evaluated with the standardized prediction errors. For such errors, the mean \pm SD obtained was $0.14 \pm 0.70 \mathrm{mgl}^{-1}$ and their $95 \%$ confidence interval $\left(-0.03,0.30 \mathrm{mg} \mathrm{l}^{-1}\right)$ included the zero value.

In addition, estimation of the interval of the predicted concentration data revealed that all concentration data observed lay within the prediction interval [PRED $\pm 2 \times$ SDpop].

\section{Pharmacokinetic-pharmacodynamic simulation}

On the basis of the results obtained in the population model, the cumulative fraction of response providing the proportion of the population that achieved an AUC : MIC ratio $\geq 400$ was estimated for several population subgroups, depending on the age and $\mathrm{CL}_{\mathrm{cr}}$ of patients. Figure 3 shows this fraction for each population subgroup and pathogen (susceptible and VISA strains of $S$. aureus) 
A

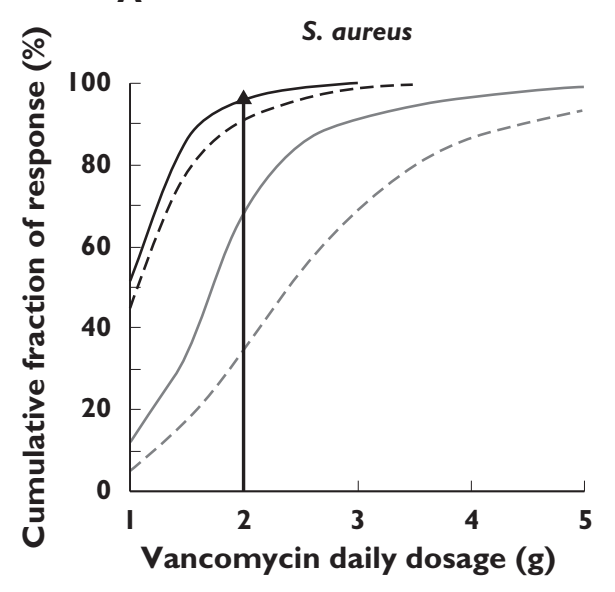

B

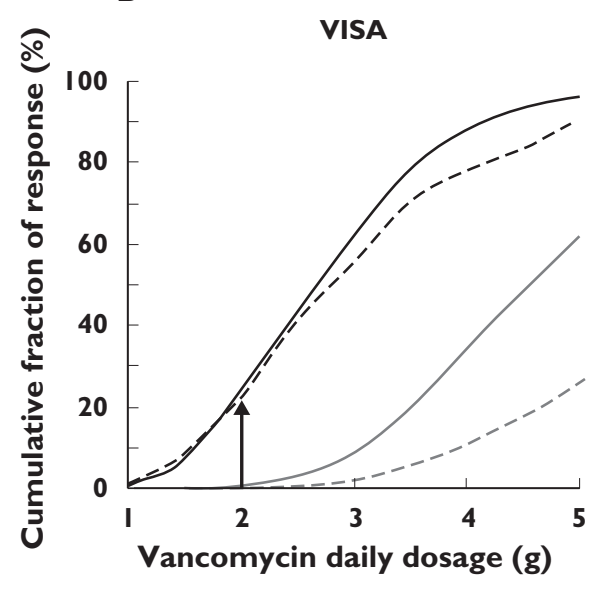

\section{Figure 3}

Cumulative fraction of response against S. aureus for several vancomycin daily doses in different ICU population subgroups: (A) For susceptible S. aureus; (B) For VISA strains. $\mathrm{CL}_{\mathrm{Cr}}$ : Creatinine clearance measured in the ICU setting $\left(\mathrm{ml} \mathrm{min}^{-1}\right) . \mathrm{CL}_{\mathrm{cr}} \leq 60 \mathrm{ml} \mathrm{min} \mathrm{m}^{-1}$ and Age $>65$ years $(-) ; \mathrm{CL}_{\mathrm{Cr}} \leq 60 \mathrm{ml} \mathrm{min}{ }^{-1}$ and $\mathrm{Age}$

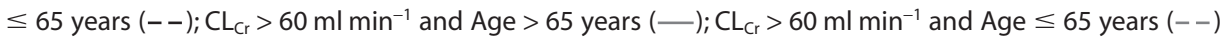

obtained with Monte Carlo simulations. As expected, the influence of the patients' renal function and age were clinically significant. Thus, for susceptible $S$. aureus $2 \mathrm{~g} \mathrm{day}^{-1}$, the standard recommended vancomycin dose, afforded an estimated cumulative fraction of response of $95.5 \%$ for patients with age $>65$ years and $\mathrm{CL}_{\mathrm{Cr}_{\mathrm{r}}}<60 \mathrm{ml} \mathrm{min}^{-1}$ but was only $33.4 \%$ for patients with age $<65$ years and $\mathrm{CL}_{\mathrm{Cr}}>$ $60 \mathrm{ml} \mathrm{min}^{-1}$. When the simulations were done for the VISA strains, the corresponding values were only $23.9 \%$ and $0.2 \%$.

\section{Discussion}

In the present study we first obtained and validated vancomycin population pharmacokinetic parameters in a representative group of ICU patients and then we applied these to evaluate the presumed efficacy of different daily doses using a PK/PD approach via Monte Carlo simulation.

Characterization of the population vancomycin pharmacokinetic profile in ICU patients is supported by the still frequent use of this antibiotic in this setting and a generalized lack of high-quality data on vancomycin disposition in this cohort of patients [27-29]. The 'creeping' of the MICs of staphylococcal organisms now demands maximum antibiotic efficacy from modified dosing regimens [30,31], especially in the context of critically ill patients, in whom early and appropriate antibiotic therapy is an essential factor for improving clinical outcomes.

Vancomycin disposition has usually been described using the two-compartment pharmacokinetic model, but in the clinical setting limited sample acquisition, as well as focusing on trough concentrations, normally only permits one-compartmental models. Despite the poor design, these data can provide more representative results of the population studied if a large number of patients is analysed. Considering the small case series reported in the literature to date [16], the size of our study population (191 patients) appears to be adequate.

The basic population pharmacokinetic model obtained without covariates points to a larger vancomycin $V$ for ICU patients, although the available information did not allow the distributive phase to be described adequately. The extended interindividual and residual variabilities of this model emphasize the need for seeking covariates that could account for such diversity. Body weight was included in the model before the evaluation of other covariates in order to facilitate its subsequent application for vancomycin dosage individualization. Furthermore, weightcorrected pharmacokinetic parameters produced a slight improvement in fit and did not affect covariate selection.

In the final population pharmacokinetic model obtained in this study, $\mathrm{CL}_{\mathrm{cr}}$ and patient age were the most influential covariates as regards vancomycin clearance. Although this type of relationship is well known for vancomycin, the inclusion of both variables in the clearance regression equation is an unusual finding, probably owing to covariance [12]. This could be due to the use of the estimated $\mathrm{CL}_{\mathrm{Cr}}$ which necessarily takes into account age and affords a small covariate range, reducing the capacity of NONMEM ${ }^{\mathrm{TM}}$ to detect any effect. Instead, we used the $24 \mathrm{~h}$ measured $\mathrm{CL}_{\mathrm{cr}}$, which is the most effective way to calculate renal function in ICU populations, affording a wide $\mathrm{CL}_{c r}$ range for which no age or weight is required. Another explanation could be that marked changes in the renal function of ICU patients due to a range of factors, such as sepsis, patient hydration status or concomitant medication usage, may mask the well known relationship between $\mathrm{CL}_{\mathrm{cr}}$ and age. We wish to emphasize that the NONMEM $^{\mathrm{TM}}$ correlation estimated between the corre- 
sponding regression coefficients $\left(\theta_{1}\right.$ and $\left.\theta_{2}\right)$ was less than $40 \%$. In fact, patient age seems to explain some additional variability in vancomycin clearance that $\mathrm{CL}_{\mathrm{cr}}$ does account for. To our knowledge, no previous population models have demonstrated a relationship between vancomycin $V$ and renal function [16, 32-35]. In the patients with $\mathrm{Cr}_{\mathrm{se}}>$ $1 \mathrm{mg} \mathrm{dl}^{-1}, V$ was more than twofold higher than in the patients with a $\mathrm{Cr}_{\mathrm{se}}$ value below this threshold (2.03 vs. $\left.0.82 \mathrm{I} \mathrm{kg}^{-1}\right)$. This result is coherent with observed trends of increased $V$ values for patients with renal insufficiency [36]. In the present study, the large increase in $V$ found in patients with $\mathrm{Cr}_{\mathrm{se}}>1 \mathrm{mg} \mathrm{dl}^{-1}$ could possibly reflect the influence of critical illness [16, 32, 33,37].Thus, in our cohort of patients with $\mathrm{Cr}_{\mathrm{se}}>1 \mathrm{mg} \mathrm{dl}^{-1}$ we observed higher values for hydration status, the Apache II score and age, as well as a greater proportion of patients with septic shock and hypoalbuminaemia. In addition, the intermediate models also pointed to the possible influence of those variables ( $P$ $<0.05$ ) on $V$ (see Table 2). The high $V$ typically seen in ICU patient populations has generally been ascribed to fluid shifts but may also be increased by the presence of other events such as hypoalbuminaemia, mechanical ventilation and extracorporeal circuits [37].

Our results point to general rather than populationspecific covariates as predictors of vancomycin pharmacokinetic parameters. This is in agreement with other adult population studies published for this antibiotic using nonlinear mixed-effect models (Table 5) showing $\mathrm{CL}_{c_{r}}$ age and weight as the only covariates influencing vancomycin disposition. Our final population model afforded comparable results for interindividual variability on $\mathrm{CL}(30 \%)$, the lowest interindividual variation for $V(23 \%)$, and similar residual variability. These figures, in a broad heterogeneous group of patients such as the critically ill, cannot be considered high. Interindividual variability is characteristic of ICU populations and the reported values are significantly higher than those typically seen in patient populations not admitted to the ICU [39]. In a similar but smaller ICU population, higher variability, possibly due in part to methodological issues, has also been reported [12].

The results concerning the external evaluation of the population pharmacokinetic model guarantee its predictive ability with a minimum bias and $100 \%$ of concentrations within the prediction interval. Analysis of the predictability of several $a$ priori methods of vancomycin dosing reveals differences of 2.5 to $5 \mathrm{mg} \mathrm{l}^{-1}$ between predicted and measured trough concentrations and less than $50 \%$ of data within the 25 and $50 \%$ interval prediction [40].

From our external evaluation, the population model could be used to estimate individualized dosage guidelines with a Bayesian approach for ICU patients. It should be noted that alternative models available for this specific patient population are flawed by methodological issues (two-stage approach and sampling size) $[12,16]$. However, the size of our population study is clinically adequate

\section{Table 5}

Vancomycin population pharmacokinetic studies in adult patients using the nonlinear mixed-effects modelling approach

\begin{tabular}{|c|c|c|c|c|}
\hline $\begin{array}{l}\text { Population } \\
n / \text { patient type }\end{array}$ & $\begin{array}{l}\text { Regression equation } \\
\mathrm{CL}\end{array}$ & $\begin{array}{l}\text { Regression equation } \\
V\end{array}$ & $\begin{array}{l}\text { Residual } \\
\text { variability }\end{array}$ & REF \\
\hline $\begin{array}{l}191 \\
\text { ICU }\end{array}$ & $\begin{array}{l}\mathrm{CL}\left(\mathrm{ml} \mathrm{min}{ }^{-1} \mathrm{~kg}^{-1}\right)= \\
0.67(7) \times \mathrm{CL}_{\mathrm{Cr}}\left(\mathrm{ml} \mathrm{min}^{-1} \mathrm{~kg}^{-1}\right)+\mathrm{AGE}^{-0.24(7)} \\
\omega_{\mathrm{CL}}(\%)=30.13(16)\end{array}$ & $\begin{array}{l}V\left(\mid \mathrm{kg}^{-1}\right)=0.82(3) \times 2.49(10)^{\mathrm{A}} \\
\mathrm{A}=0 \text { or } 1 \text { if } \mathrm{Cr} \leq 1 \text { or } \mathrm{Cr}>1 \mathrm{mg} \mathrm{dl}^{-1} \\
\omega_{V}(\%)=22.83(39)\end{array}$ & $\pm 4.2 \mathrm{mg} \mathrm{l}^{-1}(10)$ & This study \\
\hline $\begin{array}{l}215 \\
\text { Haematological malignancies }\end{array}$ & $\begin{array}{l}\mathrm{CL}\left(\mid \mathrm{h}^{-1}\right)= \\
1.08(2.12) \times \mathrm{CL}_{\mathrm{Cr}}\left(\mid \mathrm{h} \mathrm{h}^{-1}\right) \\
\omega_{\mathrm{CL}}(\%)=28.1(15)\end{array}$ & $\begin{array}{l}V(I)=0.98(7.43) \times \mathrm{TBW} \\
\omega_{V}(\%)=37.15(48)\end{array}$ & $\pm 3.5 \mathrm{mg} \mathrm{l}^{-1}(15)$ & [32] \\
\hline $\begin{array}{l}102 \\
\text { Cardiothoracic surgery, } \\
\text { unstable renal function }\end{array}$ & $\begin{array}{l}\mathrm{CL}\left(I \mathrm{~h}^{-1}\right)= \\
2.97(3) \times\left(1+0.0205(3) \times\left(\mathrm{CLCr}_{\mathrm{r}}-\mathrm{CL}_{\mathrm{Cr} \text { median }}\right)\right) \\
\omega_{\mathrm{CL}}(\%)=27(16)\end{array}$ & $\begin{array}{l}V\left(1 \mathrm{~kg}^{-1}\right)=1.24(5) \\
\omega_{V}(\%)=36(24)\end{array}$ & $\begin{array}{l}15 \%(19) \\
\pm 1.6 \mathrm{mg} \mathrm{l}^{-1}(18)\end{array}$ & [33] \\
\hline $\begin{array}{l}398 \\
102 \text { patients pertaining } \\
\text { to the above study }\end{array}$ & $\begin{array}{l}\mathrm{CL}\left(\mathrm{I} \mathrm{h}^{-1}\right)= \\
2.99(1.9) \times\left(1+0.0154(4.3) \times\left(\mathrm{CL}_{\mathrm{Cr}}-\mathrm{CL}_{\mathrm{Cr} \text { median }}\right)\right) \\
\omega_{\mathrm{CL}}(\%)=27(14)\end{array}$ & $\begin{array}{l}V_{c}\left(\mathrm{~kg}^{-1}\right)=0.675(1.8) \\
\omega_{V}(\%)=15(40) \\
V_{p}\left(I \mathrm{~kg}^{-1}\right)=0.732(0.7) \\
\omega_{V}(\%)=130(20)\end{array}$ & $\begin{array}{l}15 \%(7) \\
\pm 1.6 \mathrm{mg} \mathrm{I}^{-1}(7.7)\end{array}$ & [38] \\
\hline $\begin{array}{l}45 \text { (18 adults) } \\
\text { ( } 0 \text { days-61.5 years) } \\
\text { ECMO }\end{array}$ & $\begin{array}{l}\text { If Age }>1000 \text { days }(2.7 \text { years }) \\
C L\left(\mid h^{-1} k^{-1}\right)=4.3(5.58) / \mathrm{Cr}_{\mathrm{Se}}\left(\mu \mathrm{mol} \mathrm{I} \mathrm{I}^{-1}\right) \\
\omega_{\mathrm{CL}}(\%)=25(\mathrm{NR})\end{array}$ & $\begin{array}{l}\text { If Age }>4000 \text { days }(11 \text { years) } \\
V_{c}\left(\mathrm{~kg}^{-1}\right)=0.37(11) \omega_{V c}(\%)=25 \text { (NR) } \\
V_{p}\left(\mathrm{~kg}^{-1}\right)=0.25(15) \omega_{V p}(\%)=48 \text { (NR) }\end{array}$ & $\begin{array}{l}12.1 \%(\mathrm{NR}) \\
\pm 2.1 \mathrm{mg} \mathrm{l}^{-1}(\mathrm{NR})\end{array}$ & [34] \\
\hline $\begin{array}{l}190 \\
\text { Adult Japanese }\end{array}$ & $\begin{array}{l}\text { If } \mathrm{CL}_{C r}<85\left(\mathrm{ml} \mathrm{min}^{-1}\right) \mathrm{CL}\left(\mathrm{l} \mathrm{h}^{-1}\right)=0.0487(6) \times \mathrm{CL}_{\mathrm{Cr}} \\
\text { If } \mathrm{CL} \mathrm{Lrr}>85\left(\mathrm{ml} \mathrm{min}^{-1}\right) \mathrm{CL}\left(\mathrm{h} \mathrm{h}^{-1}\right)=3.51(6) \\
\omega_{\mathrm{CL}}(\%)=38.5(10)\end{array}$ & $\begin{array}{l}V_{s S}(I)=60.71(6) \\
\omega_{V}(\%)=25.4(11)\end{array}$ & $23.7 \%(5)$ & [35] \\
\hline $\begin{array}{l}30 \\
\text { ICU }\end{array}$ & $\begin{array}{l}\mathrm{CL}\left(\mid \mathrm{h}^{-1}\right)= \\
0.034(35) \times \mathrm{CL}_{\mathrm{Cr}}\left(\mathrm{ml} \mathrm{min}^{-1}\right)+0.015(53) \times \mathrm{TBW} \\
\omega_{\mathrm{CL}}(\%)=29.2(28)\end{array}$ & $\begin{array}{l}V c(I)=0.414(7) \times \mathrm{TBW} \\
\omega_{V}(\%)=36.4(24) \\
V \mathrm{p}(I)=1.32(20) \times \mathrm{TBW} \\
\omega_{V}(\%)=39.8(22)\end{array}$ & $\begin{array}{l}23.9 \%(32) \\
18.5 \%(38)\end{array}$ & [16] \\
\hline
\end{tabular}

The estimation error of the parameters (CV\%) is shown in brackets. A two-compartment model was used for the four latter models. ECMO, patients receiving extracorporeal membrane oxygenation; NR, not reported; TBW, total body weight; $W$, interindividual variability. 
and its simple structure should allow easy implementation in clinical software and its application in dosage individualization.

Pharmacokinetics could be an important constituent of antibiotic efficacy by predicting drug exposure, but pharmacodynamic goals and pathogen susceptibility must also be considered to ensure clinical efficacy. Accordingly, the second aim of this study was to integrate the variability associated with the pathogenic agent into the pharmacokinetic analysis. Several PK/PD indices have recently emerged as surrogate markers for successful clinical outcomes of antibiotic therapy, and they combine patientspecific PK parameters and their variability with specific susceptibility data concerning the strain of microorganism in question. The MIC values and their associated variability can be obtained within the typical clinical setting or from surveillance databases, such as EUCAST. Using this kind of data, Monte Carlo simulations have been implemented as useful techniques to predict the proportion of patients in different population groups who will achieve the desired PK/PD target when different strains or pathogens are treated.

One previous study in patients with haematological malignancies using a similar PK/PD approach and the same MIC distribution values reported similar results concerning vancomycin underdosing and hence the need to incorporate PD information into the PK analysis [41]. However, the specific population pharmacokinetic model used here is another important issue, implying that different dosage requirements and patient covariates must be considered. Also, the increased information available from a larger sample size provides support to previous studies and defines dosage needs more precisely.

In our ICU patients, the AUC of vancomycin was mainly dependent on renal function and age, and hence Monte Carlo simulation was performed for several subgroups in order to obtain the doses required to achieve the presumed most favourable outcome related to an AUC : MIC ratio greater than 400 . For S. aureus, in a typical young ICU patient (age $<65$ years and $\mathrm{CL}_{\mathrm{rr}}>60 \mathrm{ml} \mathrm{min}^{-1}$ ) the administration of $2 \mathrm{~g}$ daily as the initial vancomycin dose afforded only a $33 \%$ probability of attaining such a result; this figure increased up to $95 \%$ when the patient admitted to ICU was aged 65 years or more and his/her $\mathrm{CL}_{\mathrm{Cr}}$ was less than $60 \mathrm{ml} \mathrm{min}{ }^{-1}$. This simulated variation highlights how dosage individualization can affect clinical outcomes in this critical population and might explain apparent increases in clinical failures in the critical care setting. PK/PD simulation also revealed that much higher doses or an alternative antibiotic would be required for VISA strains, since even if vancomycin doses of $3000 \mathrm{mg}^{\text {day }}{ }^{-1}$ were administered only patients with a $\mathrm{CL}_{\mathrm{Cr}}$ lower than $60 \mathrm{ml} \mathrm{min}{ }^{-1}$ would be likely to achieve an AUC : MIC ratio higher than 400.

As well as showing our results concerning conducted the Monte Carlo simulations, Figure 3 could be used as a vancomycin dosing nomogram for ICU patients, taking into account renal function, patient age and the pathogen isolated. It may be seen that if a cumulative fraction of response of $90 \%$ is assumed as clinically acceptable, daily vancomycin doses of 2000 and $4000 \mathrm{mg} \mathrm{day}^{-1}$ for young patients with $\mathrm{CL}_{\mathrm{cr}}$ values of $<60$ and $>120 \mathrm{ml} \mathrm{min}^{-1}$, respectively, would be required, whereas for elderly patients with similar renal function the corresponding doses would be 1750 and $3000 \mathrm{mg}$, respectively. With the same goal, a previous study afforded only one initial vancomycin daily dose $(3000 \mathrm{mg})$ as being adequate for the same patient population [12].

It is noteworthy that our PK/PD model should aid clinicians in selecting the vancomycin dose with the highest probability of clinical success regardless of the infusionbased administration mode (intermittent or continuous). The AUC $(0,24 \mathrm{~h})$ at state-steady is only dependent on clearance and the drug amount, but is independent of both the rate and duration of infusion.

For seriously ill patients, the current guidelines issued for the monitoring of vancomycin treatment of $S$. aureus infections recommend a loading dose of 25 to $30 \mathrm{mg} \mathrm{kg}^{-1}$ to ensure an adequate exposure on day 1 of therapy [42]. The regression equations found with our population PK model can be applied in clinical practice to establish the suitability or not of that loading dose. Considering the patients characteristics (age, $\mathrm{CL}_{\mathrm{cr}}$ and $\mathrm{Cr}_{\mathrm{se}}$ ), an estimation of the half-life $\left(t_{1 / 2}=V \times 0.693 / \mathrm{CL}\right)$ and subsequent time required for steady-state to be reached (four or five times $t_{1 / 2}$ ) can be obtained. Bearing in mind our model, loading doses would be especially necessary in patients with a $\mathrm{Cr}_{\mathrm{se}}>1 \mathrm{mg} \mathrm{dl}^{-1}$.

The dosage recommendations obtained in this study clearly differ from those suggested by dosing nomograms aimed at maximizing the pharmacodynamics of vancomycin administered by continuous infusion in critically ill patients [43]. The application of these nomograms to our prototype ICU patient afforded a daily dose of 1200 or $1600 \mathrm{mg}$ to achieve mean target concentrations of 15 and $20 \mathrm{mg} \mathrm{l}^{-1}$, respectively. Whereas those authors [43] stated that such mean values should allow sufficiently high AUC values to be obtained, and hence may represent a valid approach for optimizing both pharmacodynamic efficacy targets, they did not use the AUC: MIC ratio and neither did they consider the potential impact of variations in MICs. In fact, their vancomycin dosages were based on a simple relationship between the Cockcroft-Gaultestimated $\mathrm{CL}_{\mathrm{Cr}}$ and vancomycin $\mathrm{CL}$. Another two recent papers focused on the optimization of vancomycin dosing also assumed a fixed value of $1 \mathrm{mg} \mathrm{l}^{-1}$ for the MIC in the estimation of AUC : MIC ratio $[38,44]$.

Although the evaluation of $C_{\min }$ alone may be a suboptimal method of assessing the adequacy of a vancomycin dose, current guidelines for monitoring vancomycin treatment still recommend such an approach and suggest that $C_{\text {min }}$ should always be maintained above $10 \mathrm{mg} \mathrm{l}^{-1}$ to avoid 
the development of resistance and, for complicated infections, in the range of $15-20 \mathrm{mg} \mathrm{l}^{-1}$ to improve clinical outcomes. Moreover, trough monitoring is recommended for patients receiving this latter aggressive dosing or prolonged courses of therapy and in all patients at high risk of nephrotoxicity [45]. For a pathogen with an MIC of $1 \mathrm{mg} \mathrm{l}^{-1}$ these $C_{\min }$ recommendations are able to guarantee the target AUC: MIC $\geq 400$, but the fact is that in this circumstance, or when the real MIC value is known, any pharmacokinetic strategy allows the dose to be calculated and adjusted to reach the desired target. Our approach, however, is much better when, as is usually the case in clinical practice, the MIC value is unknown and cannot be assumed.

Nevertheless, the reliability of our simulated approach is directly related to the adequacy of the population model and MIC distribution and it will not perform better or replace predictions from real data coming from measured concentrations or MICs. This, and the pharmacokinetic changes that may occur in ICU patients over time, the lack of patient outcome evaluation, and the possibility of drug toxicity are all important issues that must be borne in mind before its use in the clinical setting $[27,45]$. We therefore suggest that this initial approach could be employed, but followed by therapeutic drug monitoring to ensure the safe usage of these dosing recommendations in all clinical circumstances. In addition, therapeutic drug monitoring is a useful tool to ascertain the extent to which predefined therapeutic goals have been achieved and, if not, to guide subsequent dosage adjustment(s). In clinical scenarios with higher antibiotic MICs, the use of PK/PD dosing strategies may permit the selection of the therapeutic option with the highest probability of clinical success, although these clinical guidelines must be implemented and the corresponding better patient outcomes must be demonstrated.

In conclusion, the increased values of the clearance and distribution volumes obtained in some ICU patients would lead to vancomycin underexposure if standard dosage regimens were used. An approach considering the specific PK profile of this cohort, coupled with presumed variations in the MICs for S. aureus, may allow a more precise individualization of vancomycin dosing in order to achieve more effective antibiotic use in the ICU setting. Thus, for vancomycin-susceptible S. aureus, an initial $2000 \mathrm{mg} \mathrm{day}^{-1}$ dose of vancomycin must only be used for

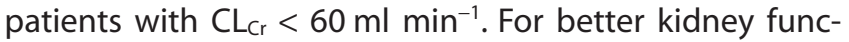
tion, the corresponding doses must be increased to 3000 and $3500 \mathrm{mg} \mathrm{day}^{-1}$ for aged ( $>65$ years) or adult patients, respectively.

\section{Competing interests}

There are no competing interests to declare.
No financial support was obtained for the preparation of this article. The authors have no conflict of interest directly relevant to the content of this study.

\section{REFERENCES}

1 Klevens RM, Edwards JR, Tenover FC, McDonald LC, Horan T, Gaynes R. Changes in the epidemiology of methicillin-resistant Staphylococcus aureus in intensive care units in US hospitals, 1992-2003. Clin Infect Dis 2006; 42: 389-91.

2 Alvarez-Lerma F. Modification of empiric antibiotic treatment in patients with pneumonia acquired in the intensive care unit. ICU-Acquired Pneumonia Study Group. Intensive Care Med 1996; 22: 387-94.

3 Rello J, Gallego M, Mariscal D, Sonora R, Valles J. The value of routine microbial investigation in ventilator-associated pneumonia. Am J Respir Crit Care Med 1997; 156: 196-200.

4 Ibrahim EH, Sherman G, Ward S, Fraser VJ, Kollef MH. The influence of inadequate antimicrobial treatment of bloodstream infections on patient outcomes in the ICU setting. Chest 2000; 118: 146-55.

5 Kollef MH. Improving outcomes in the ICU setting: are we effectively using all of the information that is potentially available to us? Chest 1999; 115: 1490-2.

6 Pea F, Viale P, Furlanut M. Antimicrobial therapy in critically ill patients: a review of pathophysiological conditions responsible for altered disposition and pharmacokinetic variability. Clin Pharmacokinet 2005; 44: 1009-34.

7 Craig WA. Pharmacokinetic/pharmacodynamic parameters: rationale for antibacterial dosing of mice and men. Clin Infect Dis 1998; 26: 1-10; quiz 1-2.

8 Moise-Broder PA, Forrest A, Birmingham MC, Schentag JJ. Pharmacodynamics of vancomycin and other antimicrobials in patients with Staphylococcus aureus lower respiratory tract infections. Clin Pharmacokinet 2004; 43: 925-42.

9 Pea F, Viale P. Should the currently recommended twice-daily dosing still be considered the most appropriate regimen for treating MRSA ventilator-associated pneumonia with vancomycin? Clin Pharmacokinet 2008; 47: 147-52.

10 Hidayat LK, Hsu DI, Quist R, Shriner KA, Wong-Beringer A. High-dose vancomycin therapy for methicillin-resistant Staphylococcus aureus infections: efficacy and toxicity. Arch Intern Med 2006; 166: 2138-44.

11 Jeffres MN, Isakow W, Doherty JA, McKinnon PS, Ritchie DJ, Micek ST, Kollef MH. Predictors of mortality for methicillin-resistant Staphylococcus aureus health-care-associated pneumonia: specific evaluation of vancomycin pharmacokinetic indices. Chest 2006; 130: 947-55.

12 Fernandez de Gatta MM, Revilla N, Calvo MV, Dominguez-Gil A, Sanchez Navarro A. Pharmacokinetic/ pharmacodynamic analysis of vancomycin in ICU patients. Intensive Care Med 2007; 33: 279-85. 
13 Drusano GL, D’Argenio DZ, Preston SL, Barone C, Symonds W, LaFon S, Rogers M, Prince W, Bye A, Bilello JA. Use of drug effect interaction modeling with Monte Carlo simulation to examine the impact of dosing interval on the projected antiviral activity of the combination of abacavir and amprenavir. Antimicrob Agents Chemother 2000; 44: 1655-9.

14 European Society of Clinical Microbiology and Infectious Diseases. The European Committee on Antimicrobial Susceptibility Testing-Eucast [online]. Available at http://www.eucast.org [last accessed 25 February 2008].

15 Dartois C, Brendel K, Comets E, Laffont CM, Laveille C, Tranchand B, Mentre F, Lemenuel-Diot A, Girard P. Overview of model-building strategies in population PK/PD analyses: 2002-2004 literature survey. Br J Clin Pharmacol 2007; 64: 603-12.

16 Llopis-Salvia P, Jimenez-Torres NV. Population pharmacokinetic parameters of vancomycin in critically ill patients. J Clin Pharm Ther 2006; 31:447-54.

17 Knaus WA, Draper EA, Wagner DP, Zimmerman JE. APACHE II: a severity of disease classification system. Crit Care Med 1985; 13: 818-29.

18 Levey AS, Bosch JP, Lewis JB, Greene T, Rogers N, Roth D. A more accurate method to estimate glomerular filtration rate from serum creatinine: a new prediction equation. Modification of Diet in Renal Disease Study Group. Ann Intern Med 1999; 130: 461-70.

19 Beal SL, Sheiner LB. NONMEM User's Guides. NONMEM Project Group. San Francisco, CA: University of California, 1989.

20 Akaike HA. Bayesian extension of the minimum AIC procedure of autoregressive model fitting. Biometrika 1979; 66: 237-42.

21 Mandema JW, Verotta D, Sheiner LB. Building population pharmacokinetics model. In: Advanced Methods of Pharmacokinetics An Pharmacodynamic System Analysis, ed. DÀrgenio DZ. New York: Plenum Press, 1995; 69.

22 Brendel K, Dartois C, Comets E, Lemenuel-Diot A, Laveille C, Tranchand B, Girard P, Laffont CM, Mentré F. Are population pharmacokinetic and/or pharmacodynamic models adequately evaluated. A survey of the literature from 2002 to 2004. Clin Pharmacokinet 2007; 46: 221-34.

23 Vozeh S, Maitre PO, Stanski DR. Evaluation of population (NONMEM) pharmacokinetic parameter estimates. J Pharmacokinet Biopharm 1990; 18: 161-73.

24 Mouton JW, Dudley MN, Cars O, Derendorf H, Drusano GL. Standardization of pharmacokinetic/pharmacodynamic (PK/PD) terminology for anti-infective drugs: an update. J Antimicrob Chemother 2005; 55: 601-7.

25 Kantzanou M, Tassios PT, Tseleni-Kotsovili A, Legakis NJ, Vatopoulos AC. Reduced susceptibility to vancomycin of nosocomial isolates of methicillin-resistant Staphylococcus aureus. J Antimicrob Chemother 1999; 43: 729-31.

26 Machain L. SimulAr: Montecarlo simulation in Excel [online]. Available at http://www.simularsoft.com.ar/ [last accessed 22 November 2007].
27 Polard E, Le Bouquin V, Le Corre P, Kerebel C, Trout H, Feuillu A, Le Verge R, Malledant Y. Non steady state and steady state PKS Bayesian forecasting and vancomycin pharmacokinetics in ICU adult patients. Ther Drug Monit 1999; 21: 395-403.

28 Pea F, Porreca L, Baraldo M, Furlanut M. High vancomycin dosage regimens required by intensive care unit patients cotreated with drugs to improve haemodynamics following cardiac surgical procedures. J Antimicrob Chemother 2000; 45: 329-35.

29 DelDot ME, Lipman J, Tett SE. Vancomycin pharmacokinetics in critically ill patients receiving continuous venovenous haemodiafiltration. Br J Clin Pharmacol 2004; 58: 259-68.

30 Pea F, Viale P. The antimicrobial therapy puzzle: could pharmacokinetic-pharmacodynamic relationships be helpful in addressing the issue of appropriate pneumonia treatment in critically ill patients? Clin Infect Dis 2006; 42: 1764-71.

31 Sakoulas G, Moellering RC Jr. Increasing antibiotic resistance among methicillin-resistant Staphylococcus aureus strains. Clin Infect Dis 2008; 46 (Suppl. 5): S360-7.

32 Buelga DS, Fernández de Gatta $M$, Herrera EV, Dominguez-Gil A, Garcia MJ. Population pharmacokinetic analysis of vancomycin in patients with hematological malignancies. Antimicrob Agents Chemother 2005; 49: 4934-41.

33 Staatz CE, Byrne C, Thomson AH. Population pharmacokinetic modelling of gentamicin and vancomycin in patients with unstable renal function following cardiothoracic surgery. Br J Clin Pharmacol 2005; 61: 164-76.

34 Mulla H, Pooboni S. Population pharmacokinetics of vancomycin in patients receiving extracorporeal membrane oxygenation. Br J Clin Pharmacol 2005; 60: 265-75.

35 Yasuhara M, Iga T, Zenda H, Okumura K, Oguma T, Yano Y, Hori R. Population pharmacokinetics of vancomycin in Japanese adult patients. Ther Drug Monit 1998; 20: 139-48.

36 Matzke GR, McGory RW, Halstenson CE, Keane WF. Pharmacokinetics of vancomycin in patients with various degrees of renal function. Antimicrob Agents Chemother 1984; 25: 433-7.

37 Roberts JA, Lipman J. Pharmacokinetic issues for antibiotics in the critically ill patient. Crit Care Med 2009; 37: 840-51.

38 Thomson AH, Staatz CE, Tobin CM, Gall M, Lovering AM. Development and evaluation of vancomycin dosage guidelines designed to achieve new target concentrations. J Antimicrob Chemother 2009; 63: 1050-7.

39 Rea RS, Capitano B, Bies R, Bigos KL, Smith R, Lee H. Suboptimal aminoglycoside dosing in critically ill patients. Ther Drug Monit 2008; 30:674-81.

40 Murphy JE, Gillespie DE, Bateman CV. Predictability of vancomycin trough concentrations using seven approaches for estimating pharmacokinetic parameters. Am J Health Syst Pharm 2006; 63: 2365-70.

41 Fernandez de Gatta MM, Santos Buelga D, Sánchez-Navarro A, Dominguez-Gil A, Garcia MJ. 
Vancomycin dosage optimization in patients with malignant haematological disease by pharmacokinetic/ pharmacodynamic analysis. Clin Pharmacokinet 2009; 48: 1-8.

42 Rybak M, Lomaestro B, Rotschafer JC, Moellering R Jr, Craig W, Billeter M, Dalovisio JR, Levine DP. Therapeutic monitoring of vancomycin in adult patients: a consensus review of the American Society of Health-System Pharmacists, the Infectious Diseases Society of America, and the Society of Infectious Diseases Pharmacists. Am J Health Syst Pharm 2009; 66: 82-98.

43 Pea F, Furlanut M, Negri C, Pavan F, Crapis M, Cristini F, Viale P. Prospectively validated dosing nomograms for maximizing the pharmacodynamics of vancomycin administered by continous infusion in the critically ill patients: the Optivanco study. Antimicrob Agents Chemother 2009; 53: 1863-7.

44 DeRyke CA, Alexander DP. Optimizing vancomycin dosing trough pharmacodynamic assessment targeting area under the concentration-time curve/minimum inhibitory concentration. Hosp Pharm 2009; 44: 751-65.

45 Lodise TP, Lomaestro B, Graves J, Drusano GL. Larger vancomycin doses (at least four grams per day) are associated with an increased incidence of nephrotoxicity. Antimicrob Agents Chemother 2008; 52: 1330-6. 